This article proposes a reflection, through visual culture, about one concrete experience with fundamental grade students from public school, in special the urgency in rethinking the school paper for working class and reclaiming its political-social dimension, by showing that students and teachers, when at the same side, can contribute for a emancipating education.

Key words: Critical pedagogy, hegemony, discourse critical analysis. 


\title{
De que lado nós estamos? \\ Uma experiência na educação de adolescentes através da cultura visual
}

\author{
Kelly Christina \\ MENDES ARANTES
}

... a tendência democrática, intrinsecamente, não pode consistir apenas em que um operário manual se torne qualificado, mas que cada 'cidadão' possa se tornar 'governante' e que a sociedade o coloque, ainda que 'abstratamente', nas condições gerais de poder fazê-lo ...

(A. Gramsci)

Este artigo propõe uma reflexão, através da cultura visual, sobre uma experiência concreta com alunos do ensino público fundamental, destacando a urgência de repensarmos o papel da escola para a classe trabalhadora e de resgatarmos a sua dimensão político-social, mostrando que, alunos e professores estando do mesmo lado, contribui para uma educação emancipadora.

Palavras-chave: Pedagogia crítica, hegemonia, análise crítica do discurso. 


\section{Introdução}

Muitas foram as perguntas que me fiz enquanto tentava criar um fio condutor para contar, de forma crítica, uma experiência vivida, em uma escola municipal durante o ano de 2005, com alunos da última etapa do $3^{\circ}$ ciclo do ensino fundamental. Minha intenção foi escrever esta experiência educativa, recorrendo a alguns referenciais teóricos, tornando-a comunicável e, ao mesmo tempo, sem transformá-la em um lugar comum, como nos mostram Hernández e Ventura (1998, p.13):

Apresentar uma experiência escolar costuma transformar-se numa reiteração de lugares-comuns, filtrados pela particularidade daqueles que a realizam. A descrição costuma ser o gênero dominante, e o esquematismo, a porta dos subentendidos que assinalam o que se fez em sala de aula. Mas isso não permite conhecer nem o que aconteceu, nem o processo de tomada de decisões que fez com que o autor ou autores tomassem aquela exata direção na experiência, e não outra qualquer.

Neste sentido, foram vários os conflitos que surgiram, na medida em que insistia em me situar nesta narração, como professora-pesquisadora e não como uma especialista ou como uma pesquisadora, que analisa os dados estando fora. Queria contar esta história estando dentro, assumindo uma postura política, que indicasse a necessidade de nós, professores do ensino fundamental, aprendermos a contar as nossas experiências e incrementarmos o nosso sentido profissional, como forma de nos tornarmos mais críticos e abertos para aprendermos a partir do nosso próprio trabalho (HERNÁNDEZ; VENTURA, 1998).

Sendo assim, me perguntava: Como escrever sobre uma experiência de maneira que a realidade desta experiência, não se transformasse simplesmente em um texto acadêmico? Como não perder as tonalidades da experiência, como nos aponta Hernández (2000, p.176), ao perguntar:

Como se pode vencer a distância entre o reflexo de uma experiência rica em matizes, carente de linearidade, e os limites que se impõem ao apresentá-la de maneira escrita, num formato que a congela e a fixa?

Ou, como contar experiências que ocorrem no âmbito do en- 
sino fundamental e no cotidiano escolar, de uma nova maneira?

Nesse sentido, seguindo na direção também apontada por Walkerdine (1998), para a necessidade de contarmos novas histórias, eu insistia na indagação: Como aprender a olhar para nós mesmos, não como o outro e sim como sujeitos fazedores de história, estando dentro e no fora dela, de maneira que esta história passasse a ser reconhecida? Como fugir aos modelos acadêmicos tradicionais que podem homogeneizar e estruturar as formas de contar uma história, distanciando-a da diversidade, do brilho e da emoção que é estar inserido na prática? Ou seja, como contar sobre a realidade da prática sem cair na forma meramente descritiva, desproblematizadora, celebradora e linear? Como registrar uma seqüência de fatos que se opõem à seqüência exigida pelos moldes tradicionais - estado da questão, metodologia, mostra das evidências, etc - ? Ou seja, como contar uma experiência que é composta de fragmentos e seqüências, em alguns momentos, e de rupturas, em outros? Enfim, como fugir aos discursos hegemônicos da cultura dominante que, através de vários meios de comunicação, produzem sujeitos à semelhança de sua própria lógica, uma lógica caracterizada pela estandardização, pela uniformidade e pela passividade, convertendo-os em seres incapazes de mediar ou negar os seus imperativos? (GIROUX; MCLAREN, 1998). E, principalmente, perguntar: por que determinados significados se constrem regularmente em volta de determinados textos e prticas culturais, alcanando assim o status de senso comum e adquirindo a qualidade de indiscutvel? (STOREY, 2002, p.172).

Assim, caminhei em direção ao cerne de meu conflito, que refletia o meu desejo em contar esta experiência, importante e transformadora, de forma que se aproximasse verdadeiramente de meus colegas do ensino fundamental, sem cair no superficial e, ao mesmo tempo, sem cair nas armadilhas das estruturas de um texto acadêmico, que passam a ser mais importantes que a própria prática. O meu conflito se inseria entre estes dois âmbitos: a urgência de aprendermos a falar de dentro da escola que, de acordo com Zeichner (1998), somente nós professores temos este poder e, ao mesmo tempo, romper com as rígidas estruturas tradicionais, que contam histórias sobre nós, 
sobre a nossa escola e sobre os nossos alunos.

Desta forma, me localizo nesta narração, como professora-pesquisadora do ensino fundamental, como autor e como sujeito que pertence ao âmbito da educação. Âmbito dinâmico, em constante transformação, cheio de incertezas e de urgências, cheio de erros, mas também de acertos. O que, nas palavras de Hernández (1998, p. 29), nos leva a considerar que

a forma de aproximarmos do conhecimento escolar da qual aqui se trata não nos "fixa" em verdades sagradas, universais e estáveis, e sim nos situa na tentativa de encontrar o que há por trás do que parece natural e nos coloca numa atitude de incerteza frente ao papel que as diferentes linguagens que se refletem nos saberes, nas disciplinas, nas matérias, (...) representam nesse processo de dar sentido à realidade.

Assim, o que proponho, neste texto, é refletir sobre uma experiência concreta, e destacar a urgência de repensarmos a educação, da qual somos peça fundamental, mostrando como esta experiência pode contribuir para repensarmos o papel da escola para a classe trabalhadora, como também, para mostrar a importância da educação resgatar a sua dimensão político-social e, conseqüentemente, a importância de nos posicionarmos como professores com compromissos político-sociais. Além disso, espero mostrar que professores e alunos estando do mesmo lado, podem tornar a escola um espaço em que todos podem encontrar o seu lugar para aprender a ser sujeitos.

Foi pensando, na má qualidade da relação entre professor-aluno e suas conseqüências no ensino e, com a intenção de distribuir responsabilidades, que comecei a questionar qual poderia ser o papel do aluno e qual poderia ser o papel do professor, pois ambos possuem a sua parcela de responsabilidade no que diz respeito às suas funções. Com isso, não pretendo defender, de forma alguma, o papel do professor transmissor e do aluno receptor. Ao contrário, minha proposta foi construir o conhecimento juntamente com os alunos, através de inúmeras situações de conflitos que surgiam durante as nossas aulas. Buscava, assim, construir outros referenciais de adolescentes, para além daqueles mostrados pela televisão e por outros meios, através de seus discursos hegemônicos. Assim, 
iniciamos um projeto utilizando, primeiramente, telenovelas e, posteriormente, filmes e artigos que nos possibilitaram discutir criticamente a construo da identidade do adolescente e do jovem adulto atravs da cultura visual.

\section{Lendo esta experiência educativa através da pedagogia crítica na perspectiva dos Estudos Culturais}

Alguns autores consideram o surgimento dos Estudos Culturais (EC) na Inglaterra dos anos 50, por terem se constituído, neste período, como disciplina, em conseqüências $s$ mudanas na formao social (...) sustentadas pelo ciclo expansivo do capital no segundo ps-guerra (CEVASCO, 2003, p.68), assim como, por um conjunto de publicações' que definiam uma nova direção aos estudos dos meios de produção cultural, no sentido de deslocar a poltica nos meios de produo para a poltica nos meios de representao (STEELE, T. ${ }^{2}$ citado por CERVASCO, 2003, p.72). Giroux (1996), ao contrário, destaca que Williams (1921-1988), um dos fundadores desta disciplina, contestava os artigos de enciclopédia que datam o nascimento dos estudos culturais a partir deste ou daquele livro publicado nos finais dos anos cinqenta.

O deslocamento da perspectiva em torno ao ensino de arte e literatura e sua relação com a história e a sociedade contemporânea, começou com a educação de adultos, não se deu em nenhum outro lugar. Foi ao chegar às universidades através das pessoas que haviam tido esta experiência, que [os Estudos Culturais] foi conhecido, repentinamente, como disciplina (WILLIAMS ${ }^{3}$ citado por GIROUX, 1996, p. 207)

Deste modo, os EC irão surgir na Inglaterra nos anos 30 e 40, diretamente do trabalho pedagógico que estava sendo desenvolvido na educação de adultos. A especificidade do conteúdo e o contexto da educação de adultos proporcionou, aos $E C$, várias questões que os conduziram para seus posteriores desenvolvimentos, já como disciplina, em Birmingham Centre for Culture Studies, na décadas de 50 e 60. Estas questões incluíam, segundo Giroux (1996): 
...a negativa em aceitar as limitações das estruturas de poder e os limites acadêmicos estabelecidos, a exigência de vincular a literatura com as situações vitais dos estudantes adultos e a insistência em que a escolarização fosse capacitadora e não meramente humanizadora (p.207)

É desta forma, portanto, que Giroux (1996) propõe recuperar uma pedagogia que se converta em um ato de produção cultural, numa forma de escrita onde as pessoas de verdade possam expressar e reescrever suas experiências vividas dentro e não fora da história. Neste sentido, a importncia da pedagogia para o contedo e contexto dos estudos culturais radica na relevncia que tem para iluminar como o conhecimento e as identidades sociais se produzem em diversos lugares, entre os que se incluem as escolas (GIROUX, 1996, p.208). Deste modo, os interesses dos EC vêm: marcados na histria, pela ênfase na história dos de baixo; das mdias, pelas relações dos meios de comunicação com a sociedade; e da sociologia, pelo interesse ampliado pela etnografia e pelas subculturas (CEVASCO, 2003). Sem nunca perder de vista que, os EC se devem desenvolver não somente em relação com as especificidade e a natureza dinâmica dos problemas e conflitos que abordam, mas também, em relação ao legado de sua história, enquanto prtica poltica e oposicionista (GIROUX, 1996).

Assim, a pedagogia crítica na perspectiva dos Estudos Culturais nos servirá de base teórica para a análise desta experiência, onde o conceito de hegemonia é crucial para ajudar-nos a compreender as relações de poder que perpassam as diferentes configurações relacionadas à classe, ao gênero, à raa e à região. Como nos explica Storey (2002, p. 166), hegemonia para Gramsci:

é um conceito político desenvolvido para explicar (dada a natureza exploradora e opressiva do capitalismo) a ausência de revoluções socialistas nas democracias capitalistas ocidentais. Gramsci utiliza o conceito de hegemonia para referir-se a uma condio em processo que uma classe dominante (aliada com outras classes ou frações de classes) não só governa uma sociedade, mas a dirige através do exercício da liderana moral e intelectual. Neste sentido, o conceito é usado para sugerir uma sociedade em que, apesar da opressão e da exploração, existe um alto grau de consenso, uma boa parte de estabilidade social; uma sociedade em que os 
grupos e classes subordinadas parecem dar apoio ativo e subscrever valores, ideais, objetivos, significados políticos e culturais, que os unem e os incorporam às estruturas de poder prevalecentes.

A experiência educativa que passo à analisar visa desconstruir identidades de adolescentes e jovens adultos veiculadas pela mídia ${ }^{4}$ (televisão, cinema, revistas, entre outros meios). Com isso, propus, inicialmente, refletirmos sobre a forma que as estruturas dominantes de comunicação de massa produzem significados mascarados, contribuindo assim, para estabilizar as convenções e naturalizá-las tomando-as como dadas (WODAK, 2004). Desta forma, o conceito de hegemonia clarifica como o poder cultural pode penetrar dentro do terreno da vida cotidiana, transformando-a em uma luta e acomodao da cultura dos grupos subordinados (GIROUX; MCLAREN, 1998, p.185). Na medida em que questionávamos estes discursos hegemônicos, percebíamos que era possível construir uma outra escola, através de uma pedagogia crítica, onde a resistência dos sujeitos pode romper com as convenções e práticas discursivas estáveis, através de atos de criatividade (FAIRCLOUGH ${ }^{5}$, citado por WODAK, 2004).

Iniciamos este processo, desconstruindo, explicitamente, as identidades dos adolescentes e jovens adultos, difundidas pela mídia. Porém, implicitamente, dentro deste mesmo processo, buscava desconstruir, também, a identidade dada ao professor do ensino fundamental, ou seja, um profissional técnico, que não precisa pesquisar mas, manipular os livros textos. Busquei na teoria crítica subsídios para compreender a realidade e, assim, despertar a nossa consciência de que, com freqüência, somos enganados à respeito de nossas próprias necessidades e interesses (WODAK, 2004). Desta forma, à medida que, juntos, descobríamos e construíamos outras possíveis identidades, arriscávamos penetrar em um mundo ainda não explorado e, com isso, me constituía como professora-pesquisadora. Como nos mostra Hernández (1998, p. 39):

Tudo isso para favorecer o desenvolvimento de estratégias de indagação, interpretação e apresentação do processo seguido ao estudar um tema ou um problema que, por sua complexidade, favorece o melhor conhecimento dos alunos e dos docentes de si mesmos e do mundo em que vivem. 
Construímos conhecimento, na medida em que arriscávamos e experimentávamos, contrariando o que muitos especialistas prescrevem como certo e seguro, como explicita Kincheloe (1997, p. 28), eles [os especialista] parecem não se dar conta de que o ensino é inerentemente um ato de incerteza, e que qualquer tentativa para negar esta característica acaba em problema.

Estamos acostumados a ler histórias que só deram certo e não histórias que deram certo, porque ocorreram muitos problemas que, geralmente, não são mencionados. Neste caso, conhecer uns aos outros, nos darmos o respeito e levar os alunos a se darem respeito, para começarem a conhecer a si mesmos, leva tempo! Neste processo, o professor é o coordenador, é quem leva os alunos a pensar sobre o que eles sabem e o que eles poderiam saber de forma mais sofisticada, de forma político-social contextualizada. Para isso, é indispensável que nossos alunos aprendam a ler, não como um processo de submissão à autoridade do texto,

...mas como um processo dialético de compreensão, crítica e transformação. Eles necessitam escrever e reescrever as histórias no texto em que lêem, como para ser capazes de uma melhor compreensão, identificação e direção, para trabalhar ativamente na construção de suas próprias histórias e vozes. A interpretação do texto deve ser uma forma de aprendizagem de como eleger, como construir a voz e como situar-se na história (GIROUX; MCLAREN 1998, p. 155-156).

Este projeto, desenvolvido com quatro turmas da última etapa do $3^{\circ}$ ciclo, não atingiu $100 \%$ dos alunos. Nas diferentes salas, houve alunos que me deram muitas respostas, outros que tinham mais dificuldade de se manifestarem e, outros ainda, que não estavam dispostos a interagir. Houve momentos em que paramos para refletir se desejávamos continuar ou não. Os alunos participavam de todo o processo, a escolha era sempre deles. A eles cabia escolher o lugar que desejavam ocupar neste processo: participantes, atuantes e/ou observadores, não atuantes. Estas posições eram discutidas entre todos, sem juízos de valor, de certo ou errado. Discutíamos as possibilidades, mas a escolha era do aluno. Pretendíamos que essa escolha fos- 
se consciente, que levasse em conta a faixa etária do aluno e, com isso, sua maturidade. Houve semanas em que os debates foram fervorosos, outras em que os ânimos estavam exauridos. Tivemos altos e baixos, o que faz parte da dinâmica escolar, assim como da vida.

Embora tivéssemos um tema central que nos conduzia, este projeto não estava fechado para os inúmeros imprevistos que surgiram ao longo de seu desenvolvimento. A seqüência foi se delineando a partir das respostas e indagações dos alunos em nossas interações. Assim, como professora também pesquisei e aprendi.

Deste modo, pretendo narrar uma experiência positiva, acreditando que uma outra escola é possível, sem descartar os conflitos existentes em nossa realidade.

\section{Análise Crítica do Discurso e a Pedagogia Crítica na perspectiva dos Estudos Culturais}

A análise crítica do discurso ( $A C D$ ) não possui um marco teórico unitário. Em suas variantes encontram-se marcos teóricos e conceituais estreitamente relacionados, em que, as noções de poder, domínio, hegemonia, ideologia, entre outras, são importantes para as análises de diferentes discursos como, por exemplo, em nosso caso, de alguns discursos representados através da mídia (VAN DIJK, 1999).

Desta forma, a ACD e a pedagogia crítica na perspectiva dos Estudos Culturais se interagem subsidiando uma leitura crítica dessa experiência educativa. Sendo assim e, de acordo com Van Dijk (1999, p. 23), a ACD:

... estuda primariamente o modo em que o abuso do poder social, o domínio e a desigualdade são praticados, reproduzidos, e ocasionalmente combatidos, pelos textos e a fala no contexto social e político. A análise crítica do discurso (...) toma explicitamente partido, e espera construir de maneira efetiva a resistência contra a desigualdade social.

A ACD defende que toda a pesquisa é poltica no sentido lato, e que não só deve contribuir para mudanças sociais, como também, para avanços teóricos e analíticos dentro de seu próprio campo (VAN DIJK, 1999). 
Nesta perspectiva, pretendo deixar claro que não assumo uma postura neutra diante de meus alunos e que tenho consciência da minha história e do lugar que ocupo, como professora-pesquisadora, pertencente à classe trabalhadora. Em outras palavras, crucial para os analistas crticos do discurso a conscincia exp/cita de seu papel na sociedade (VAN DIJK, 1999, p. 23).

Portanto, assumir uma postura neutra, onde o sujeito não é considerado autor de sua história e transformador do seu contexto, mas uma mera conseqüência, é contrariar toda a minha proposta pedagógica, que defende a contraposição de idéias como etapa do processo de construção de conhecimento e de transformação dos sujeitos envolvidos. E que, neste caso, não se limita a considerar as posturas do professor-pesquisador e dos teóricos culturais, mas também, as posturas e opiniões dos alunos.

Desta forma, minha intenção é situar teoricamente esta experiência, na perspectiva da pedagogia crítica proposta pelos Estudos Culturais que, juntamente com a ACD, pretende contribuir para dotar de poder a quem carece dele, com o fim de ampliar o marco da justia e da igualdade sociais (VAN DIJK, 1999, p. 24).

\section{Indo além das nossas identidades subjetivas}

Incorporar uma visão crítica que levasse os alunos a perguntar a quem beneficia determinada visão dos fatos e a quem marginaliza, assim como, introduzir em nosso estudo, opiniões diferenciadas, de maneira que o aluno compreendesse que a realidade se constrói desde pontos de vistas diferentes e que alguns se impõem frente a outros, nem sempre pela força dos argumentos mas pelo poder de quem os estabelece (HERNÁNDEZ, 1998), foi uma das diretrizes que se foi configurando nas nossas discussões em sala de aula.

Assim, o primeiro cuidado, no início do projeto, foi prestar atenção nos programas que estes jovens assistiam na televisão, a mídia mais acessível, para depois, levar até eles, a mídia não acessível, contrapondo as diferentes formas de focar o mesmo 
tema, e desta maneira, questionar o por quê de uma dada situação e de outra. Neste sentido, Giroux e McLaren (1998, p. 167) nos alertam para a urgência em desenvolvermos uma pedagogia crítica, que

dote aos estudantes de contra-discursos ou "posições" de sujeito de resistência - em síntese, de uma nova linguagem de análise - mediante as quais eles possam assumir uma distância crítica de suas posições de sujeito mais familiares, com o fim de comprometerem-se com uma práxis melhor idealizada para promover um projeto de transformação social.

Nesta direção, propus problematizarmos as relações entre o que ns somos de fato na realidade e que identidades assumimos através dos discursos dos meios de comunicação de massa e da mídia. Estas identidades correspondiam à nossa realidade?

Assim, discutimos o tema da identidade não como um significado absoluto, mas em relação aos seus diferentes aspectos, atravs dos quais o conceito de identidade dirige a ateno para um sentido mais elaborado de poder da cultura e a relao da cultura com o poder (GILROY, 1998, p. 64-65) ${ }^{6}$. Nossas discussões nos levaram para além de nossas identidades subjetivas, nos colocando diante da questão da poltica cultural destacada por Gilroy (1998, p. 65), que

é algo mais importante que o frágil eco da política cultural dos tempos do passado. Esta política cultural se aplica tanto à crescente notoriedade da identidade (como problema que aparece na vida cotidiana), como a identidade mesma, pois está manejada e controlada pelas indústrias culturais da comunicação de massas, que transformaram a compreensão do mundo e o lugar dos possuidores individuais de identidade dentro do mesmo.

Desta forma, nosso interesse foi se dirigindo para o sentido de identidade solidria. Como nos explica Gilroy (1998, p. 71), "este aspecto da identidade tem que ver com a forma em que as conexões e as diferenças se convertem em bases sobre as quais se pode provocar a ação social". Portanto, já não estávamos, tratando o tema da identidade como subjetividade, que destaca a história do sujeito e sua subjetividade, representadas pelas relações complexas que penetram a difcil fronteira exis- 
tente entre os campos psicolgicos e sociolgicos. Também, não estávamos considerando a identidade enquanto igualdade, que tem seus aspectos psicológicos e psicanalíticos, que questiona como um sujeito ou pessoa pode chegar a ver-se a si mesmo atravs dos outros. Neste caso, as relações que formam os sujeitos avançam a sua individualidade histrica, para o pensamento de identidades coletivas e comunais: naes, gneros, geraes, grupos raciais e tnicos (GILROY, 1998).

Embora estes dois aspectos da identidade enquanto subjetividade e igualdade sejam diferentes, eles se sobrepõem e nos conduziram ao terceiro aspecto da identidade, destacado também por Gilroy (1998), o aspecto da identidade enquanto solidariedade, pois como veremos mais adiante, este aspecto levou os alunos participantes desta experiência, de diferentes raas (brancos e negros), de diferentes religiões (católicos e evangélicos), de diferentes regiões (periferia e favela), de diferentes idades e gêneros à uma ação social envolvendo, inclusive, alunos que não fizeram parte do projeto.

Iniciamos nossas discussões a partir de observações sobre a relação entre os alunos e entre eles e os professores, que não estava muito boa na escola. A sensação era que estávamos uns contra os outros e não lutando todos por um mesmo ideal. Isto nos levou a perceber que, o fato de não nos conhecermos e de nos relacionarmos através de identidades pré-estabelecidas para professores e para alunos, nos impedia de iniciarmos um diálogo mais maduro, pois nos afirmávamos mais, do que nos questionávamos. Conseqüentemente, isso nos levava ao desenvolvimento de um saber mnimo, como destaca Frigotto (1984, p. 205-206):

Objetivamente, dentro da história da educação brasileira, notamos que os trabalhadores tiveram a não-escola, a escola desqualificada, a escola que ignora e despreza seu saber acumulado ou escolas paralelas, do tipo SENAl, cuja pedagogia específica é a própria pedagogia do capital que busca fazer pelas mãos a cabeça do trabalhador.

Com Frigotto percebi que este saber mnimo, incorporado por muitos docentes do ensino fundamental, através dos discursos hegemônicos das classes dominantes, não fazia o me- 
nor sentido dentro de uma perspectiva pedagógica crítica. Pois uma pedagogia crítica deve converter-se num significado de contra-hegemonia. Mais especificamente, deve converter-se em um método teorético estratégico para desvelar a forma como as contradições ideológicas são resolvidas no nível imaginário do sujeito individual (GIROUX: MCLAREN, 1998, p. 229).

Na contramão desta pedagogia crítica e de acordo com os discurso hegemônicos, percebo que, quando se desenvolvem projetos sociais que envolvem a Cultura Visual (artes plásticas, cinema, televisão, produção de imagens através de fotos ou vídeos, etc.), quase sempre se adota uma perspectiva assistencialista, acrítica, que busca resultados paliativos em comunidades desfavorecidas, para diminuir o índice de violência. Nestes casos, as técnicas de como se produz uma imagem, costumam ser mais importantes que as relações de poder que estas imagens mediam.

Este tipo de análise costuma ocorrer sob o prisma das visões de grupos hegemônicos, que levam os participantes desse processo a ter uma visão sobre si mesmos mediada por aqueles que os vêem de fora, tornando-se, assim, cúmplices das estruturas de poder exploradoras e opressivas prevalecentes.

Em oposição a estas formas tradicionais de tratar a imagem, o que buscávamos, era compreender como a análise da cultura visual pode ir além da superfície ou da decomposição analíticocompositiva do tipo formal (linhas, texturas, etc.) (HERNÁNDEZ, 2000). Este mesmo autor nos esclarece que a compreensão da cultura visual implica:

aproximar-se de todas as imagens (sem limites demarcados pelos critérios de um gosto mais ou menos oficializado) e estudar a capacidade de todas as culturas para produzi-las no passado e no presente com a finalidade de conhecer seus significados e como afetam nossas vises sobre nós mesmos e sobre o universo visual em que estamos imersos. (HERNÁNDEZ, 2000, p. 51)

Esta relação está na base das discussões realizadas em nosso projeto. Utilizamos o cinema, a televisão, alguns textos e, inclusive, recorremos a uma sessão de entrevista para analisar a hegemonia de certos grupos dominantes, sobretudo, daqueles que detém os meios de comunicação no Brasil. Por exemplo, a 
série Malhao ${ }^{7}$, citada em diferentes momentos de nossas aulas e acompanhada, diariamente, pela maioria dos alunos, serviu de mediação para várias relações com outros tipos de discursos e, conseqüentemente, com a nossa realidade. Esta proposta exigiu que eu assistisse e comentasse com os alunos, sempre que surgia uma oportunidade, a minha leitura, ou seja, a minha análise crítica de alguns capítulos dessa série. Com este exercício de relacionar os discursos produzidos por diferentes meios, descobrimos que, em alguns casos, "as interconexões e as redes de causa e efeito podem ser distorcidas a ponto de saírem do nosso campo de visão. Assim, a atividade crítica consiste, essencialmente, em tornar visível a natureza interligada das coisas". (FAIRCLOUGH ${ }^{8}$ citado por WODAK, 2004)

\section{O controle do contexto}

Usamos, como exemplo de controle de contexto, a escola onde acontecem as principais tramas em Malhao. Bastante moderna e sofisticada, seus alunos, além de salas de aulas confortáveis, têm também um centro de esportes com piscina. Contrapondo opiniões, podíamos ver que, na série Malhao, algumas formas de controle do contexto, são trabalhadas em favor dos interesses de grupos hegemônicos através de diferentes categorias, como nos mostra Diamond (1996): ${ }^{9}$

o contexto consiste em categorias como a definição global da situação, seu espaço e tempo, as ações em curso (incluindo os discursos e seus gêneros), os participantes em papéis variados, comunicativos, sociais ou institucionais, assim como, suas representações mentais: objetivos, conhecimentos, opiniões, atitudes e ideologias. Controlar o contexto implica controlar uma ou mais dessas categorias, determinando o estatuto ${ }^{10}$ da situação comunicativa, dizendo sobre o tempo e o lugar do acontecimento comunicativo, ou sobre que participantes podem ou não estar presentes nele, e em que papéis, ou sobre que conhecimentos ou opiniões terão ou não terão, e sobre que ações sociais podem ou não cumprir-se através do discurso (Citado por VAN DIJK, 1999, p. 27).

Um outro exemplo de uma destas categorias, também se pode observar em relação ao número reduzido de atores negros, estes são sempre colocados à margem das tramas prin- 
cipais. Como nos explica Van Dijk (1999), as minorias não só gozam de menor acesso aos discursos da elite, como atores ou expertos, como também são discriminadas quando tentam entrar nas instituições da elite. Além disso, podíamos perceber que a ética e a solidariedade nem sempre são praticadas e o egoísmo e a competição são o destaque. Beijar na boca o sonho mximo" do jovem adulto, além de estarem totalmente alienados ao que se passa em sua volta. Sem destacar a infantilização dos atores (jovens adultos) que atuam como adolescentes e para quem, de acordo com a ideologia burguesa, a responsabilidade só deve ser exercida quando estiverem inseridos no mercado de trabalho, como nos explica Frigotto (1984, p. 58):

Para a economia burguesa não interessa o homem enquanto homem, mas enquanto um conjunto de faculdades a serem trabaIhadas para que o sistema econômico possa funcionar como um mecanismo. Todas as características humanas que dificultam o funcionamento desse sistema (reflexão, ética e etc.) são indesejáveis e tidas como não-científicas. As duas características básicas, exigidas deste homem desprovido de si mesmo enquanto totalidade, são a racionalidade do comportamento e o egoísmo.

Embora a série Malhao ocorra em um contexto localizado, podendo também estar situada num micro-sistema, o seu discurso representa um grupo hegemônico que detém um importante meio de comunicação de massa, traduzindo, neste caso, o discurso de uma instituição. Assim nesta análise focalizarei a referida série situando-a no macro-sistema.

Quando comparávamos Malhao (nível-macro) com a nossa realidade escolar (nível-micro) estávamos fazendo, nada mais que "vincular o discurso institucional com a sociedade em geral e, com a desigualdade social em particular" (VAN DIJK, 1999, p. 25). Não estávamos analisando os dois níveis separadamente, mas relacionando-os. Desta forma, quando voltávamos o olhar para nossa realidade, percebíamos muita coisa diferente entre a nossa história e a história contada em Malhao. Por que alguns têm muito e outros têm pouco ou quase nada? Por que o aluno inteligente é sempre ridicularizado? Por que o estereótipo do aluno que pensa é sempre o do aluno introvertido que não consegue fazer amigos e que está fora de moda? Será que 
é de interesse da classe dominante criar um estereótipo de um adolescente inteligente, construtivo e participativo? Com isso, aproximávamos de um dos objetivos principais da ACD: "entender e analisar a reprodução do domínio e da desigualdade social que surge do discurso, e resistir contra ela". (VAN DIJK, 1999, p. 32).

Assim, podíamos observar, no contexto da sala de aula, que os estudantes participativos e com um discurso político articulado, eram discriminados por boa parte de seus colegas. O que fiz, então? Comecei a desconstruir estes estereótipos ${ }^{12}$, colocando os alunos como sujeitos atuantes no processo das discussões. Deste modo, e de acordo com a ACD, tentávamos evitar estabelecer uma relação simplista de determinação entre os discursos televisivos e o social, como forma de "resistência às relações desiguais de poder, que figuram como convenções sociais" ( WODAK, 2004, p. 2).

Em nossa sala de aula, tínhamos alunos inteligentes e participativos, alguns até mesmo super-ativos, sociáveis, com opiniões e que conseguiam elaborar um discurso claro sobre seus pensamentos. Começamos a perceber que o fato de sermos críticos não nos impedia de fazer amigos. Inclusive nós mesmos (professores), segundo Lahire (1997), construímos perfis que acabam por demonstrar harmonias e contradições entre comportamentos e qualidades morais, por um lado, e resultados escolares e qualidade intelectuais, por outro. Assim,

(...) existem alunos indisciplinados, instáveis e com desempenhos escolares medíocres; alunos disciplinados, atentos e com bom desempenho escolar; mas existem também, ainda que mais raramente, alunos razoavelmente indisciplinados e com bons desempenhos escolares, e alunos relativamente disciplinados com fraco desempenho escolar (LAHIRE, 1997, p. 55).

Aos poucos, começamos a perceber que os estereótipos construídos através dos meios de comunicação de massa colocam as múltiplas possibilidades de identidades em casulos muito bem definidos, em restritas categorias, impedindo a articulação das múltiplas possibilidades de escolha. Também, compreendemos que, não é por acaso, que a periferia é vista como um espaço de marginais e não de marginalizados e que a 
escola pública, por exemplo, é vista como um espaço do saber mnimo, portanto, não pode ser uma escola de qualidade. Com isso, íamos desvelando outros preconceitos que nos impediam de conhecer a nós mesmos, pois existe também, o estereótipo do professor da escola pública e do professor da escola particular. Alguns professores de arte, por exemplo, muitas vezes não ensinam arte na escola pública (preferem exercícios de relaxamento), em geral, porque não acreditam na capacidade de seus alunos. Alguns professores de línguas, por exemplo, que atuam em ambos os tipos de escolas, em geral, não conversam em inglês com seus alunos da escola pública, só com os alunos da escola particular. Segundo Kincheloe (1997, p. 63), "na sociedade capitalista fazem parte da classe dominante também aqueles cujos interesses coincidem com os interesses da burguesia". Por isso, pergunto, de que lado ns estamos? Não vejo a possibilidade de construir um Brasil justo sem a escola pública abraçar uma pedagogia crítica que apoie,

(...) os alunos, os professores e os administradores a desenvolver uma visão moral e ética, prática fundamentada em uma política da diferença que permaneça criticamente atenta às diferentes vozes das quais falam os estudantes. A pedagogia crítica ajuda estas vozes a problematizar-se e a transformar-se em direção aos interesses da justiça social e cultural (GIROUX; MCLAREN, 1998, p. 227).

No momento em que passamos a estar alertas à sedução do espaço extremamente ordenado da escola da série Malhao e começamos a prestar atenção nas relações que ocorriam entre aquele contexto (geral) e o nosso contexto (particular), percebíamos que: $O$ que bom esteticamente pode ser mal politicamente, e o que mal esteticamente, poder ser bom politicamente (STOREY, 2002, p. 279).

Nessa direção, propus uma reflexão aos meus alunos sobre o que eles faziam com as representações de adolescentes e de jovens adultos, mediadas pela mídia, ou o que eles faziam a partir destas imagens (STOREY, 2002, p. 276). Desta forma, não estávamos lidando com verdades únicas e inquestionáveis, uma vez que a mídia e, mais especificamente, os meios de comunicação de massa consolidam valores e reafirmam a dife- 
rença a partir do momento que mobilizam certas formas de visualidades para uma determinada maneira de ver e ordenar o mundo (ROSE, 2001). Ao contrário, pretendi mostrar, aos meus alunos, diferentes formas de ver o mundo e tentar o que Rose chama de tarefa crtica, ou seja, levá-los a diferenciar os efeitos sociais de diferentes visões de mundo.

\section{Rompendo o controle do contexto}

Vimos três filmes-chave que contavam a história de jovens em contextos bastante distintos e com atitudes surpreendentes, em alguns dos casos. Por exemplo, em Edukators (Alemanha, 2004), três jovens politizados questionavam as injustiças do sistema capitalista e, em Maria Cheia de Graa (Colômbia, 2004), a personagem principal encontra uma brecha na perversidade do sistema sócio-político em que vivia, para sair em busca de uma vida digna. Explorei, também, estereótipos de adolescentes bem conhecidos por eles, como no filme Aos Treze (EUA, 2004), no qual duas jovens adolescentes entraram em um esquema auto-destrutivo, provando a sua vulnerabilidade diante de um sistema que aliena os jovens, transformando-os em verdadeiros objetos.

Assim, fomos rompendo com muitos estereótipos presentes na própria sala de aula. Aprendemos, de igual modo, que suas identidades iam além do que Ihes era oferecido e que eles, também, poderiam escolher e criar outras tantas identidades. Assim, se expressou um de meus alunos quando comparou os filmes Edukators e Aos Treze:

(...) No filme [Aos Treze] apresentado podemos observar que o motivo da rebeldia da jovem Tracey foi a amizade de Evie, deixando marcas que só o tempo poderá apagar. Isso é o que presenciamos atualmente numa sociedade de jovens alienados e consumistas, que se espelham em objetos de propaganda capitalista para estarem na moda.

No filme Aos Treze ficou provado que o adolescente é muito influenciável. Eu concluo isso pela mudança de comportamento da jovem que, de menina de ouro, passou a ser menina das drogas e do sexo, justamente para entrar na moda.

Comparando o filme Edukators com Aos Treze, há uma diferença 
De que lado nós estamos?

Uma experiência na educação de adolescentes através da cultura visual

muito grande entre os jovens, pois, em Edukators, os jovens eram politizados e autocríticos, já em Aos Treze, encontramos duas jovens consumistas e influenciáveis. Mas, percebo, pelo menos em minha visão, que as atitudes dos jovens dependem da época e da situação dos pais. Concluo então, que não existe a perfeita identidade do jovem (Antônio Silva, 2005 - 15 anos).

De outra maneira, mas comparando os mesmos filmes, a aluna, Jéssica escreveu o seguinte:

O filme, Aos Treze, mostra a vida de duas adolescentes americanas sem muitas condições financeiras que acabam se tornando rebeldes sem causa. Essa história é muito diferente do filme Edukators, que mostra a realidade de três jovens europeus, que ao contrário de simplesmente se rebelarem saindo, quebrando e roubando tudo, como vítimas do sistema, se rebelam contra ele.

É exatamente esta diferença entre os dois filmes e as duas realidades retratadas neles. Os jovens de Edukators se rebelam, mas com uma causa. Eles questionam o sistema sócio/econômico em que vivem e tentam abrir os olhos das pessoas para isso. Já em Aos Treze, Evie e Tracey se tornam verdadeiros objetos e vítimas do sistema, se encaixando verdadeiramente no estereótipo designado para elas, ou seja, de adolescentes perturbadas, que só querem saber de roupas, sexo, aparência e brigas constantes com os pais. Quando Tracey e Evie pensam que estão se rebelando e sendo diferentes, não estão fazendo nada mais, que o papel já dado a elas pelo sistema e principalmente, pelos meios de comunicação. Existem formas mais construtivas e críticas de se rebelar, como por exemplo, não aceitar o estereótipo que é dado a você. Se cada um entender isso, e se rebelar a sua maneira, é claro! De maneira crítica e construtiva, a sociedade já melhoraria bastante. É claro que isso não basta para resolver todos os problemas, mas ia ajudar muito (Jéssica Martins, 2005 - 15 anos).

Estes dois textos foram trabalhados com todas as turmas que estavam participando do projeto. No primeiro, destaquei a percepção do aluno no sentido de que não existe uma identidade perfeita e única e que, enquanto desconstruíamos estas identidades fixas, na verdade estávamos reconstruindo nossas subjetividades, ou seja, começávamos a perceber que nossas experiências incluem diferentes tipos de relações e que as formas culturais disponíveis legitimam algumas e marginalizam outras. Desta forma, foi possível, aos alunos, perceber que eles 
estavam construindo novas maneiras de ver o mundo, mais crítica e mais política.

No segundo texto, destaquei a clareza com que a aluna situou os dois filmes, indicando uma forma construtiva de se rebelar. Com isso, tornamos o pedagógico político, utilizando formas de pedagogia que incorporavam interesses políticos emancipadores; isto é, utilizamos de formas de pedagogia que tratam os alunos como agentes críticos e com capacidade para abrir-se à análise e à pesquisa (GIROUX; MCLAREN, 1998).

\section{Os filmes e as telenovelas}

Com o intuito de aprendermos a relacionar diferentes conhecimentos em diferentes contextos, continuamos nossos exercícios comparativos entre os filmes que assistíamos e as telenovelas que estavam acontecendo naquele momento. Relacionamos, por exemplo, o filme Maria Cheia de Graa com a novela $A$ Lua me Disse. O primeiro mostrava o contexto da jovem Maria que vivia numa condição de miséria e exploração. Grávida de um namorado que não amava, ela sustentava sua família sem pai. Na novela, três jovens haviam se engravidado sem planejamento, sendo que, uma delas, além da gravidez indesejada, também, teve que abdicar de sua carreira promissora como jogadora de futebol, dando prioridade, a ser mãe. Desta forma, víamos como o papel do texto e da fala, dentro do discurso televisivo, podem reproduzir a desigualdade de gêneros, consolidando uma estrutura social conservadora, tradicional e patriarcal. Embora, na novela, este tema pudesse ter sido aberto para discussões mais profundas o que presenciamos foi um acomodamento da situação, mesmo porque, todas as três personagens contavam com o apoio de suas respectivas famílias. Então, propus que refletíssemos sobre a situação das adolescentes no filme Maria Cheia de Graa e na novela A Lua Me Disse:

Maria Cheia de Graa, entre os três filmes assistidos, talvez seja o filme que conte uma história que esteja mais próxima da nossa realidade latino-americana, porém, Maria, a personagem principal, possui a sua própria ideologia e tira proveito da precariedade de 
sua vida, para tentar escapar da miséria. Oprimida pela família e pela estrutura econômico-social, a qual pertence, ela luta, à sua maneira, pelo seu sonho e pelo seu futuro.

Já, a novela $A$ Lua Me Disse parece mostrar que a gravidez na adolescência é uma coisa normal e não discute este problema. A idéia que passa é que o sonho de se realizar primeiro profissionalmente, para depois ter uma família mais estruturada não deve ser muito importante para as jovens. São as meninas que, geralmente, abdicam de seus sonhos, para construir uma família, às vezes, menos estruturada que a de seus pais. Assim, se prolifera a ignorância e as más condições de vida, tornando-as parte, de uma classe facilmente governada e à margem.

A partir desta reflexão propus aos meus alunos que fizessem uma síntese do que eles pensavam sobre o tema. Minha intenção foi possibilitar a eles informações, que a maioria de seus colegas não têm acesso e mostrar outras formas de contextualizar o tema da gravidez na adolescência. Mostrar, por exemplo, que as conseqüências de uma gravidez indesejada, principalmente, para as meninas, significaria manter-se em um espaço de opressão. E que os textos e as falas televisivas no representam meramente uma funo lingstica ou comunicativa, (expressando ou transmitindo significados), mas poltica (VAN DIJK, 1993, p. 272). Assim,

(...) não somente é importante conhecer como as imagens se apresentam, senão para quem estão sendo dirigidas, ou seja, o que importa não é a imagem em si mesma e sim como são vistas por determinados espectadores, a que tipo de olhar convidam? Considerando que estamos sempre vendo as relações entre as coisas e nós mesmos (ROSE, 2001, p. 11).

Além de fazermos comparações entre os três filmes (Edukators, Maria Cheia de Graa e Aos Treze) que contavam sobre a vida de jovens rebeldes da classe trabalhadora e de destacar a realidade da America Latina, também discutimos sobre outras realidades (América do Norte e Europa). Realidades localizadas, mas que permitiam diálogos com realidades mais abrangentes, que enfatizavam diferentes posturas de adolescentes e jovens adultos, quebrando o estereótipo do adolescente rebelde e sem causa. 
Partindo dessas relações, propus aos alunos uma discussão em grupo em que apontassem semelhanças e contradições entre os filmes Edukators e Maria Cheia de Graa. Um dos grupos assim se expressou:

... Mas também há diferenças, talvez mais diferenças que semeIhanças. Dentre elas, vemos que enquanto os jovens de Edukators, além de serem totalmente politizados, eles não lutavam para eles mesmos. Eles lutam por melhorias para todos. Já a jovem de Maria Cheia de Graa não tenta mudar a política de onde ela vivia, ela sai de seu país a procura de um lugar onde fosse totalmente diferente de onde ela vivia, para conseguir uma vida melhor para ela e para toda a sua família (Geferson, Luís, Joana, Lorena e Felipe 2005). (O grifo é meu).

Estes filmes mostraram como as características de um jovem podem ser diversas e múltiplas, ao contrário do que é destacado pelos meios de comunicação de massa, que coisificam o sujeito, na medida em que transformam em consumidor e consumível. Daí, ser tão evidente a exacerbação dos jovens como objeto de desejo. Para eles estar na moda é o bastante para criar a ilusão de que suas necessidades estão sendo satisfeitas.

Desta maneira, o projeto foi tomando corpo e, à medida em que discutíamos, os alunos iam tendo acesso a informações alternativas e se situando diante dos problemas abordados. E adquirindo, desta forma, o conhecimento e as crenas necessrias para desafiar os discursos ou as informaes a que esto expostos (VAN DIJK, 1999, p. 29).

\section{Possibilitando crenças alternativas}

Minha intenção ao analisar os filmes foi ampliar o universo destes alunos para além do discurso televisivo. Em muitos casos, no existem outros discursos ou meios que provenham informaes das quais possam derivar crenas alternativas (VAN DIJK, 1999).

Buscando criar outras crenas, intercalamos nossas aulas com debates, leituras, escritas, sessões de filmes e uma entrevista, onde convidamos uma alemã da antiga Alemanha Oriental, para relatar sua experiência neste país. 
A entrevista ocorreu na nossa escola, foi um momento muito rico para todos nós. Pois, permitiu-nos ampliar nossos conhecimentos e matar algumas curiosidades, onde muitos mitos foram esclarecidos. Já havíamos assistido o filme Edukators e, assim, os alunos puderam fazer comparações entre a vida no Brasil e a vida na Alemanha e se surpreender quando a nossa convidada Ihes contou que foi, somente, na sua adolescência, que seus pais compraram uma televisão. Essa foi a parte que mais alvoroço causou, já que para um jovem brasileiro a televisão faz parte de todas as etapas de sua vida.

Outro tema que permitiu um contraste, entre a vida no Brasil e na Alemanha, foi sobre a esperança que o brasileiro deposita nos governos, persuadido pelos discursos da elite dominante aparentemente simpticos, democrticos ou populistas. Em geral, estes discursos, segundo Van Dijk (1993), legitimam os grupos dominantes, na medida em que sinalizam semanticamente o dominante através de uma auto-apresentação positiva e o Outro através de uma apresentação negativa ou depreciativa. Conseqüentemente, os primeiros se auto-legitimam como melhores capacitados para decidir o que é melhor para todos. Assim, na Alemanha unificada, segundo a entrevistada, os cidadãos são mais participativos politicamente, ou seja, não ficam esperando de braços cruzados que os governantes solucionem todos os seus problemas de forma paternalista. Isso significa que, eles também atuam para que as mudanças ocorram em vez de ficar reclamando.

Nessa perspectiva, propus aos alunos que refletissem sobre o lugar que eles ocupavam e o lugar que eles gostariam de ocupar, em relação não só ao espaço físico, mas também, à classe social, ao tipo de ensino que têm acesso e a tantas outras coisas que eles não tinham e que continuam não tendo acesso, sem nunca perder de vista, evidentemente, as relações de poder entre as classes. Assim, outros problemas foram levantados como, por exemplo, o fato de que freqüentar a escola não garante a eles, melhores condições de vida, principalmente, quando essa escola não é de qualidade. Frigotto (1984), vinte anos atrás, já discutia esta questão:

O que se observa concretamente é que a classe burguesa não 
se contrapõe ao acesso à escola. A universalização do acesso legitima a aparente democratização. O que efetivamente se nega são as condições objetivas, materiais, que facilitem uma escola de qualidade e o controle da organização da escola (FRIGOTTO, 1984, p. 166).

Nessa direção, Kincheloe (1997) vai ao encontro de Frigotto quando, fazendo uma crítica às reformas educacionais que vêm de cima, de acordo com os interesses das classes dominantes, afirma que: a noo de democracia se reduz a um conjunto de princpios herdados que ensinam aos professores (e aos estudantes) a adaptar mais do que questionar os arranjos sociais e institucionais que eles encontram (p. 45). Assim, propus ao grupo que iniciássemos uma reflexão sobre qual seria a responsabilidade dos alunos e dos professores, diante da escola e da sociedade.

Ainda que, alguns alunos não conseguiram perceber o significado de nossas discussões, esta experiência atingiu a maior parte das turmas, que demonstraram em suas respostas que nossas reflexões foram bastante positivas, principalmente, pelo fato de nosso projeto extrapolar a nossa sala de aula.

\section{A prática do discurso contra-hegemônico através de identidades solidárias}

No dia 28 de outubro de 2005 ocorreu um fato inédito na história de nossa escola. Os alunos, da $3^{a \underline{a}}$ etapa do $3^{\circ}$ ciclo, se organizaram, autonomamente, inclusive envolvendo alunos de outras etapas, para reivindicar um direito: ter professores. Em nossa escola, já entrávamos no terceiro mês letivo sem professores de Ciências, Inglês e Matemática. Estes alunos conseguiram mobilizar uma das redes de televisão de maior audiência no Brasil, com amplo poder na construção de estereótipos, para reivindicar seus direitos. Assim, foi ao ar no MG TV seus depoimentos. Não houve, diretamente, nenhum adulto envolvido neste fato. O surpreendente foi que os alunos inverteram as regras. E em um intervalo de tempo muito pequeno, conseguiram armar, o que Foucault (1992), ao discutir relações de poder, denomina de o grande jogo da histria: 
Quem se amparará das regras, quem ocupará o lugar daqueles que as utilizam, quem se disfarçará para pervertê-las, utilizá-las ao contrário, e utilizá-las contra aqueles que as haviam imposto; quem, introduzindo-se no complexo aparato, o fará funcionar de tal modo que os dominadores se encontrarão dominados por suas próprias regras (FOUCAULT, 1992, p. 17-18).

Neste sentido, posso afirmar que, a partir do momento em que a reivindicação dos estudantes se tornou público, não eram mais os alunos que estavam em desvantagem e prejudicados pela falta de professores, mas a Secretaria Municipal de Educação, pelo descaso com que vinha tratando o problema. A reivindicação foi atendida. No mesmo dia, após a manifestação, já tínhamos à nossa disposição um professor de matemática.

Podia-se ouvir, um dia antes deste acontecimento, um certo burburinho na escola, porém, o que ninguém imaginava, era que esta atitude tomaria tal dimensão. Os alunos pararam por alguns minutos as atividades e se retiraram das salas de aula para se encontrarem no pátio central. Foi então, que a emissora de televisão apareceu e gravou seus depoimentos ao meio de muita agitação e de faixas onde se exigia professores para as três disciplinas.

Embora, esta manifestação tenha se dado a partir das atitudes de um grupo de adolescentes, que possivelmente, não tinham ainda maturidade para perceber a dimensão do mesmo, é interessante perceber que esta atitude representava uma luta pela vontade do saber, ou seja, pelo acesso a um saber que não está distribuído no sistema educacional, porque não está implicado numa conformidade poltica (FOUCAULT, 1992). Estes adolescentes demonstraram que, mesmo sendo filhos da classe trabalhadora, também desejam ter acesso ao conhecimento. E as prováveis conseqüências disso, nós já deveríamos saber, é o Poder. Esta experiência propicia reflexões e, também, permite uma outra leitura da história, como mais uma vez é destacado por Foucault, (1992, p. 32):

O saber acadêmico [escolar], tal e como está sendo distribuído no sistema de ensino, implica evidentemente uma conformidade política: em história, se lhes pede saber um determinado número de coisas, e não outras (...) O poder oficial sempre representou uma 
luta política dentro de uma classe social (querelas dinásticas na aristocracia, conflitos parlamentares na burguesia); inclusive como o centro de uma luta entre a aristocracia e a burguesia. Enquanto, os movimentos populares têm sido apresentados como produzidos pela fome, pelos impostos, pelos desempregos; e nunca como uma luta pelo poder, como se as massas pudessem sonhar com comer bem, mas não com exercer o poder. A historia das lutas pelo poder e, em conseqüência, as condições reais de seu exercício e de sua sustentação, segue estando quase totalmente oculta. O saber não entra nele: isso não se deve saber.

Com isso, aprendemos com os alunos que a luta por uma educação de qualidade não deve ser lembrada somente em épocas de reajuste salarial, mas diariamente. Ficou claro que a comunidade deseja um ensino de qualidade e que os alunos estão dispostos a entrar nesta luta também.

Todos estes jovens, entre 12 e 15 anos, trouxeram à tona, de forma criativa, os problemas que várias escolas da rede pública municipal vêm enfrentando, e que a nossa classe de professores não tem conseguido mostrar, porque ainda não aprendemos a ver esta realidade com os nossos próprios olhos e sim através dos olhos da cultura dominante. Ainda hoje, existem professores que não vêm relação entre prática e teoria, o que demonstra os reflexos dos discurso hegemônicos sobre suas identidades. Mais uma vez pergunto: De que lado ns estamos? Pois, como afirma Frigotto (1984, p. 180):

A desqualificação da escola, para a grande maioria que constitui a classe trabalhadora, não é uma questão conjuntural - algo, como insinua a tecnocracia, a ser redimido, recuperado por mecanismos técnicos (ou pela tecnologia educacional). Trata-se de uma desqualificação orgânica, uma irracionalidade racional, uma improdutividade produtiva, necessária à manutenção da divisão social do trabalho e, mais amplamente, à manutenção da sociedade de classes. Ou, então, como se pode entender o descaso concreto, historicamente recalcitrante, com a escolarização da classe trabaIhadora?

Desta forma, não só precisamos ressuscitar a história, como um espaço de luta, mas também, como recurso teórico para a reconstrução de uma ética da política e da possibilidade (GIROUX, 1993). A partir dos conflitos, dos diferentes discursos 
e narrações, conseguimos alcançar uma conexão fundamental entre a escola e a vida comunitária, o que, em palavras de Newlon (1941) ${ }^{13}$, significa: As crianas e os jovens somente podem aprender a converter-se em membros da comunidade sendo membros desta (citado por GIROUX, 1993, p.137).

Deste modo, acredito que o nosso projeto - A construo da identidade do adolescente e jovens adultos atravs da cultura visual - contribuiu para dotar os alunos de outras formas de leitura sobre suas realidades, ajudando-os a ver o seu entorno de outra maneira, para além dos discursos hegemônicos. Assim como também acredito que outros fatores, implícitos e explícitos, dentro e fora da escola, possam ter contribuído para estes jovens assumirem uma postura política. Esta experiência nos possibilitou perceber o poder que temos enquanto comunidade escolar e que a ideologia dominante insiste em tirá-lo de nós. Por isso, primeiro, precisamos reencontrar nosso lugar na educação, para depois sermos críticos e encorajarmos nossos alunos a sê-los também.

Através do envolvimento dos alunos em todo o processo, pude perceber que nosso projeto pedagógico superou a crítica, ou seja, foi também político, porque lhes proporcionou, através de uma linguagem tanto de crítica como de esperança, um conjunto concreto de condições de aprendizagem, graças ao qual, pudemos nos reunir para falar, dialogar, compartilhar nossas narrativas e lutarmos juntos a partir de relações sociais que fortalecem, ao em vez de debilitar, a possibilidade da cidadania ativa. Com isso, aprendemos que ao gerarmos espaços públicos em nossas salas de aula, estaremos contribuindo para a estruturação de redes solidárias, na medida em que estamos encorajando nossos alunos a lutar por uma democracia ativa, onde não há espaço para o isolamento escolar, que nega aos estudantes um vínculo entre o que eles aprendem na escola e o ambiente em que vivem fora dela (GIROUX, 1993). 


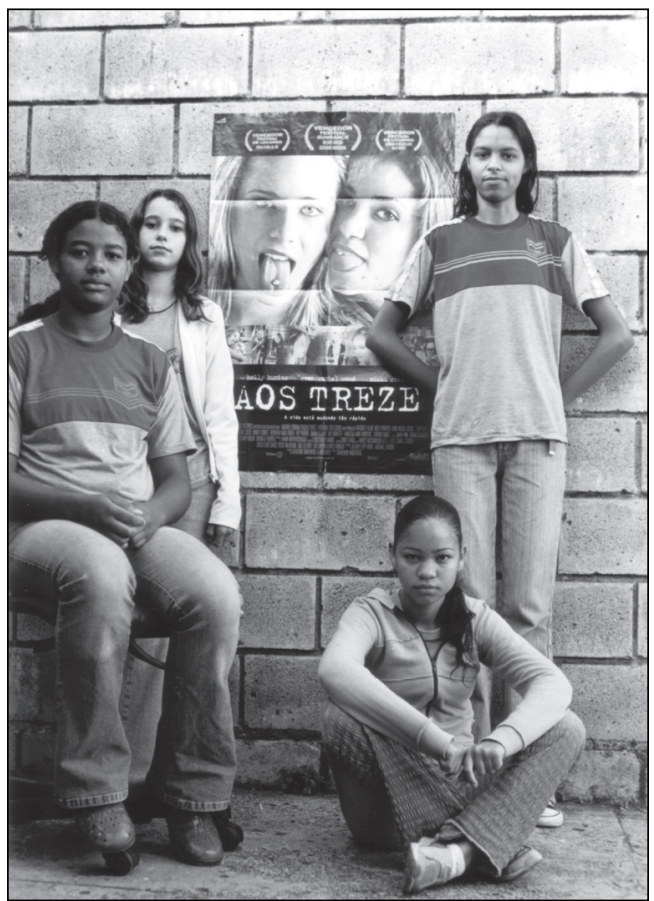

Da esquerda para direita:

Aline Bento, Jéssica Fernanda,

Claudinéia Ferreira, Selma Laine.

Fotos: Kelly Mendes

Da esquerda para direita: Maílson Ferreira, Paulo Rangel, Gleison Gomes.

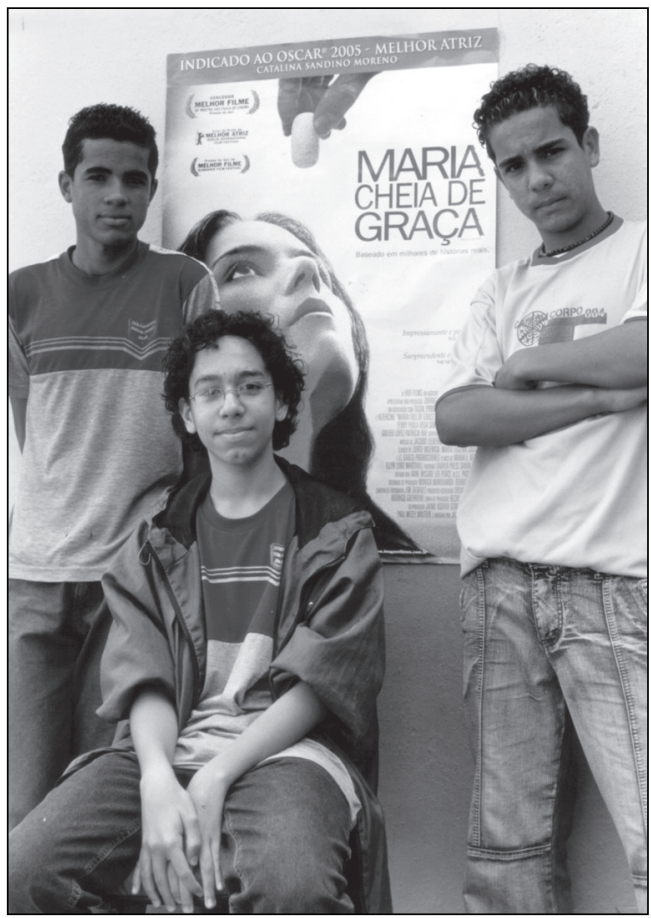


De que lado nós estamos?

Uma experiência na educação de adolescentes através da cultura visual

Foto: Kelly Mendes

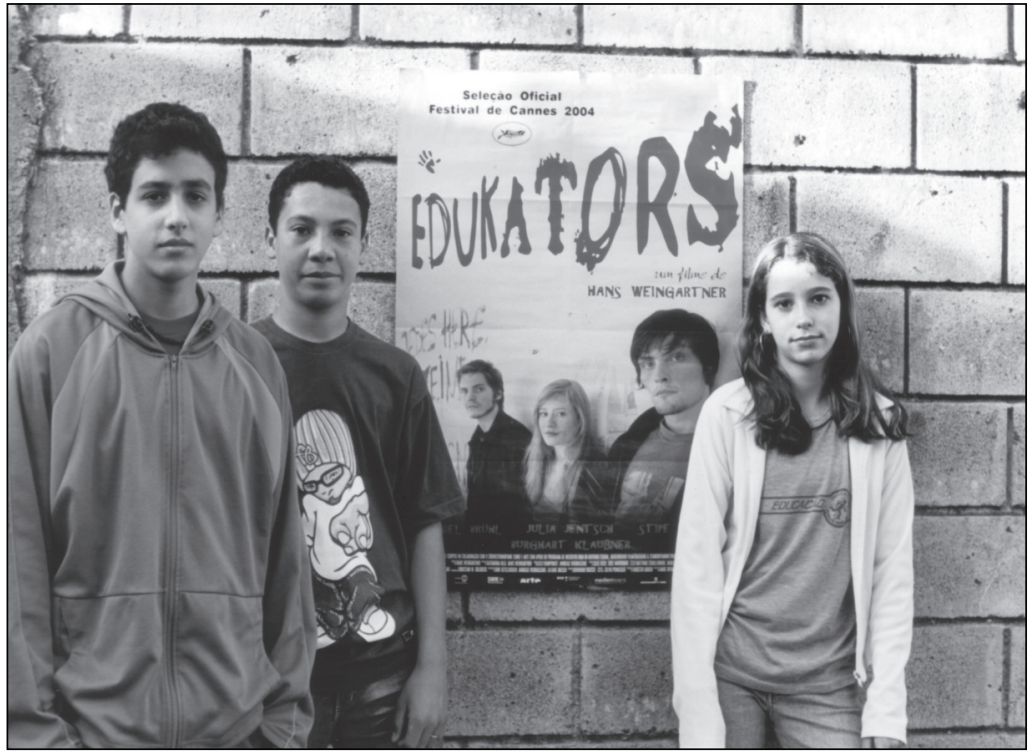

Da esquerda para direita: André Meniconi, Kelves Costa, Jéssica Fernanda.

\section{Notas}

1. Culture and Society (1958) de Raymond Willians, ao lado de, The Uses of Literacy (1957), de Richard Hoggart e de The Making of the English Working Class (1963) de Edward P. Thompson

2. STEELE, T. The Emergence of Cultural Studies. Londres, Lawrence \& Wishart, 1997, p. 204.

3. Raymond Williams, "Adult Education na Social Change", in What I Came to Say (Londres: Hutchinson-Radus, 1989), p. 157-166. Ver também Raymond Williams, "The Future of Cultural Studies", in Williams, The politcs of Modernism, Londres: Verso, 1989, p. 151-162.

4. A forma em que produtos artísticos ou culturais são feitos. Em arte, o medium referese ao material usado para criar o trabalho, tal como pintura ou pedra. Em comunicação - uma forma intermediária de passar uma mensagem. O termo medium também refere-se a tecnologias específicas, através das quais, as mensagens são transmitidas: rádio, televisão, filmes, etc. O termo media em inglês é o plural de medium, mas freqüentemente usado no singular, como em the media (A Mídia) para descrever a constelação das industrias da mídia que juntas influenciam a opinião pública.

5. FAIRCLOUGH, N. e KRESS, G. Critical Discourse Analysis. Mimeo, 1993. 
6. Para uma compreensão mais aprofundada do conceito de identidade e sua ressonância dinâmica baseada nos estudos críticos, ver Gilroy (1998).

7. Desde de 1995 a série Malhação inaugurou um novo formato de teledramaturgia voltada para o público jovem. A partir de então, a cada ano trás novos elencos, novas histórias e novos cenários. Embora proponha discutir temas de interesse dos jovens, o enfoque nunca chega a ser verdadeiramente crítico.

8. Ver Fairclough (1985).

9. DIAMOND (1996).

10. Conjunto de normas que regem a organização e vida de uma coletividade.

11. Como destacou uma aluna em uma de nossas discussões.

12. Concepção simplificada normalmente aceita que se tem a respeito de alguém ou algo.

13. NEWLON (1941).

\section{Referências}

A LUA me disse. Direção de Denis Carvalho. Rio de Janeiro: Rede Globo de Televisão, 2005. Telenovela.

AOS TREZE. Direção de Catherine Hardwicke, roteiro de Catherine Hardwicke e Nikki Reed, produção de Jeffrey Levy-hinte e Michael London, música de Mark Mothersbaugh, fotografia de Elliot Davis, edição de Nancy Richardson. EUA/Inglaterra: Working Title Films / Antidote Films / Venice Surf club / Michael London Productions, 2003. DVD (101 minutos), son., color.

CEVASCO, M., E. Dez Lies Sobre Estudos Culturais. 1. ed. São Paulo: Boitempo, 2003.

DIAMOND, J. Status and power in verbal interaction. A study of dicourse in a clase-knit social network. Amsterdam, Benjamins, 1996.

DIJK, V. El Análisis Crítico del Discurso. Revista Anthropos, Barcelona, n.186, p.23-36, set-out. 1999.

DIJK, V. Principles of Critical Discourse Analysis. Discourse \& Society, v.4, London: Sage, 1993: p. 249-283.

EDUKATORS. Direção de Hans Weingartner, roteiro de Katharina Held e Hans Weintgartner, produção de Antonin Syoboda e Hans Weintgartner, música de Andreas Wodraschke, fotografia de Daniela Knapp e Matthias Schellenberg, música de Andreas Wodraschke, edição de Dirk Oetelshoven e Andreas Wodraschke. Alemanha: Celluloid Dreams / IFC Films / Lu- 
De que lado nós estamos?

Uma experiência na educação de adolescentes através da cultura visual

mière, 2004. 126 minutos, son., color. Legendado. Port.

FAIRCLOUGH, N. Critical and descriptive goals in discourse analysis. Journal of pragmatics, n. 9, p.739-763, 1985.

FOUCAULT, M. Microfsica del Poder. 3. ed. Madrid: La piqueta, 1992.

FRIGOTTO, G. A Produtividade da Escola Improdutiva. 1. ed. São Paulo: Cortez, 1984.

GILROY, P. Los estudios culturales británicos y las trampas de la identidad. In: CURRAN, J; MORLEY, D; WALKERDINE, V. (orgs.). Estudios Culturales: Análisis, producción y consumo de las políticas de identidad y el postmodernismo. 1. ed. Barcelona: Paidós, 1998: p.63-83.

GIROUX, H. La Escuela y La Lucha por la Ciudadana. 1. ed. Madrid: Siglo Veintiuno, 1993

GIROUX, H. Placeres Inquietantes: Aprendiendo la cultura popular. 1.ed. Barcelona: Paidós, 1996.

GIROUX, H; McLAREN, P. Sociedad, Cultura y Educacin. 1. ed. Madrid: Miño y Dávila, 1998.

HERNÁNDEZ, F. Transgresso e mudana na educao: Os projetos de trabaIho. 1. ed. Porto Alegre: ArtMed, 1998.

HERNÁNDEZ, F; VENTURA, M. A Organizao do Currculo por Projetos de Trabalho: O conhecimento é um caleidoscópio. 5. ed. Porto Alegre: ArtMed, 1998.

HERNÁNDEZ, F. Cultura Visual, mudana educativa e projeto de trabalho. 1. ed. Porto Alegre: ArtMed, 2000.

KINCHELOE, Joe L. A Formao do Professor Como Compromisso Poltico: Mapeando o Pós-Moderno. 1. ed. Porto Alegre: ArtMed, 1997.

LAHIRE, Bernard. Sucesso Escolar nos Meios Populares: As razões do improvável. 1.ed. São Paulo: Ática, 1997.

MALHAÇÃO. Direção de Ricardo Waddington. Rio de Janeiro: Rede Globo de Televisão, 2005. Telenovela.

MARIA CHEIA DE GRAÇA. Direção de Joshua Marston, roteiro de Joshua Marston, produção Paul S. Mezey, música de Leonardo Heiblum e Jacobo Lieberman, fotografia de Jim Denault, desenho de produção de Debbie Devilla, edição de Anne McCabe e Lee percy. EUA/Colombia: Fine Line Features / Imagem Fimes, 2004. DVD (101 minutos), son., color.

NEWLON, J. Democracy or super-patriotism?, The Social Frontier, 7:59 (abril de 1941), p. 210.

ROSE, Gillian. Visual Methodologies. 1. ed. Londres: Sage, 2001.

STOREY, John. Teora Cultural y Cultura Popular. 1. ed. Barcelona: Octaedro, 2002. 
STURKEN, M. e CARTWRIGHT, L. Practices of Looking: An introduction to visual culture. 1. ed. New York: Oxford, 2001.

WALKERDINE, V. Sujeto a cambio sin previo aviso: la psicología, la posmodernidad y lo popular. In: CURRAN, J; MORLEY, D; WALKERDINE, V. (orgs.). Estudios Culturales: Análisis, producción y consumo de las políticas de identidad y el postmodernismo. 1. ed. Barcelona: Paidós, 1998, p. 153-185.

WODAK, Ruth. Do que trata a ACD - um resumo de sua história, conceitos importantes e seus desenvolvimentos. Revista Linguagem em (Dis)curso, número especial, v.4, p.01-13, 2004.

ZEICHNER, K. M. Para além da divisão entre professor-pesquisador e pesquisador acadêmico. In: GERALDI, C. Ma G; FIORENTINI, D; PEREIRA, E. M. de A. (orgs.). Cartografia do trabalho docente: professor(A) - pesquisador(A). 1. ed. Campinas. Mercado de Letras, 1998, p. 207-236.

\section{KELLY CHRISTINA MENDES ARANTES}

Docente da Escola Municipal Oswaldo França Júnior em Belo Horizonte, Doutoranda no programa de Educação Artística: Ensino e Aprendizagem das Artes Visuais pela Universidade de Barcelona. Email: crazykelly68@ hotmail.com. 